\title{
Bemerkungen zur Stratigraphie des mitteleuropäischen Jungpleistozäns
}

\author{
Von Hansjürgen Müller-Beck, Bern \\ Mit 3 Abbildungen im Text \\ Inhalts übersicht
}

I. Einführung
A. Vollgliederungsversuche mit Hilfe von $\mathrm{C}^{14}-\mathrm{Daten}$
B. Die terminologischen Grundlagen
C. Hauptzüge der gegenwärtigen Diskussion

II. Archäologische Beobachtungen

A. Die jungpleistozäne Stratigraphie in Nordwest-Frankreich

B. Paläolithische Leitstationen in Mitteleuropa
1. Weimar - Ehringsdorf
2. Lebenstedt
3. Willendorf
4. Achenheim
5. Stetten - Vogelherd
6. Unter-Wisternitz
7. Pollau

C. Stratigraphische Folgerungen in Mitteleuropa

III. Schluß.

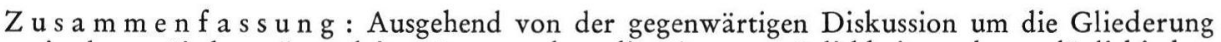
des mitteleuropäischen Jungpleistozäns werden die Aussagemöglichkeiten der paläolithischen Hauptfundstellen des Gebietes untersucht. Als stratigraphisches Ergebnis läßt sich einerseits das Voll-Interglazial (Eem mit Antiquusfauna), andererseits das Voll-Glazial mit einer relativ kurzen Schwankung (Bildungszeit der beiden obersten Jüngeren Löße) hinreichend fixieren. Das klassische Würm (im Sinne von A. PENK \& E. BRÜCKNER 1909) kann offenbar nur mit dem obersten Jüngeren Löß nach der voll-glazialen Schwankung in etwa parallelisiert werden. Zwischen Voll-Interglazial und Voll-Glazial liegt eine sehr wahrscheinlich langdauernde schwankungsreiche Übergangsperiode, für die die Bezeichnung $\mathrm{Jungple}$ is toz änes An aglazial vorgeschlagen wird. Sie umfaßt einerseits das Spät-Interglazial (mit Mammutfauna), andererseits das Früh-Glazial (mit regional beschränkter Lößbildung). Innerhalb des Anaglazials sind $\mathrm{meh} \mathrm{rere}$ kleinere und größere Klimaschwankungen zu erwarten. Archäologisch sind Voll-Interglazial und Anaglazial in Mittcleuropa mit keineswegs einheitlichen spät-altpaläolithischen moustéroiden Inventaren verbunden. Kulturträger dürften vorwiegend neandertaloide (anthropologisch ebenfalls kaum einheitliche) Menschenformen gewesen sein. Das Auftreten des echten Jungpaläolithikums („Aurignacien typique") erfolgt erst mit Beginn des Voll-Glazials kurz vor der voll-glazialen Schwankung.

A b s r a c t : As a result of a reexamination of a couple of the most important archaeological sites of Upper Pleistocene age in Middle Europe the following climatic evolution can be given as proofed:

1. A full-interglacial phase (with antiquus-faune)

2. A full-glacial phase with a relative short oscillation enclosed (sedimentation of the two upper "Younger Loesses"). It seems as if the classical „Wurm" in the sense of A. PENCK - as given in the Alpine moraines of Upper Pleistocene age - will be connected only with the upper part of the full-glacial stage after the full-glacial oscillation (Abb. 3).

Between Full-Interglacial and Full-Glacial a long lasting periode of indifferent climate is to be put in. For this stage the terminus $\mathrm{A} \mathrm{nagla} \mathrm{cial}$ is proposed. This anaglacial time comprehends the Upper-Interglacial (with primigenius-faune) and the Early-Glacial with an until now unknown number of smaller or bigger oscillations and periodes of regional, mostly limited, loess-sedimentations. 
Archaeologically the Full-Interglacial and the Anaglacial are both connected with very differenciated moustéroide old-palaeolithic culture complexes all over Middle Europe. The first true upper-palaeolithic culture (Aurignacien typique = Aurignacien moyen) is in the area not older than the beginning of the Full-Glacial, shortly before the full-glacial oscillation spoken about.

\section{Einführung}

A. Vollgliederungsversuche mit C $14-D a t e n$

Durch die in ständig steigender Zahl zur Verfügung stehenden $C^{14-D a t i e r u n g e n ~ s p a ̈ t-~}$ quartärer Profilglieder ist die bisher unerledigte Diskussion un die stratigraphische Gliederung des Jungpleistozäns wieder intensiviert worden. Besonders H. Gross (1956, 1957, 1958) hat sich bemüht, mit Hilfe der ihm zugänglichen $C^{14}$-Daten eine Vollgliederung des mitteleuropäischen Jungpleistozäns vorzulegen. Trotz einiger unbedingt notwendiger Umstellungen folgt er dabei weitgehend der auf W. Soergel zurückgehenden Terminologie und Auffassung der stratigraphischen Folge. Ansätze zu einer auf C14-Daten aufbauenden jungpleistozänen Stratigraphie gibt auch Hl. DE VRIEs (1958) mit Hilfe einiger von ihm durchgeführter Messungen. Auffallend ist dabei, daß sich beide Autoren, obwohl sie im allgemeinen im mitteleuropäischen Bereich auf den gleichen Einzelheiten aufbauen, in der zusammenfassenden Auswertung nicht unerheblich widersprechen. So stellt zum Beispiel H. Gross $(1957,1958)$ den Zeitraum 33000-42000 vor heute (31-40000 v.Chr.) in sein "Göttweiger Interstadial“, also eine Wärmeschwankung, während Hl. DE VRIES (1958) den genau gleichen Zeitraum als relativ kalt bezeichnet und unter Beiziehung der Ergebnisse von Brörup (Sv. Th. Andersen 1957, H. Tauber \& Hl. De Vries 1958) dic Ưbereinstimmung mit „Göttweig “ nicht unbedingt als gegeben ansieht.

Dieser Gegensatz verliert natürlich erheblich an Gewicht, wenn man sich vergegenwärtigt, daß praktisch alle bisher verfügbaren jungpleistozänen Radiocarbon-Daten aus amputierten und zudem noch faziell sehr unterschiedlichen Profilfolgen stammen. Ein Vergleich zwischen ihnen ist ohne Einführung hypothetischer Verbindungen - vor allem bei Zeitangaben älter als 30000 Jahren - bisher nicht möglich. Man kann sich durchaus auf den Standpunkt stellen, daß es am richtigsten wäre (so ctwa H. Lindner 1957), erst einmal eine möglichst große Zahl absoluter Datierungen abzuwarten, um einen Überblick über die Gleich- oder Ungleichzeitigkeit der verschiedenen jungpleistozänen Bildungen zu bekommen. Auf der anderen Seite scheint es aber doch möglich, schon mit Hilfe der bisher vorhandenen und erprobten Kriterien einen gewissen Gesamtrahmen der Vorgänge abzustecken. Unwahrscheinliche Interpretationen von $\mathrm{C}^{14}$-datierten Schichtgliedern ließen sich so besser vermeiden, systematische Datierungsarbeiten wären vielleicht leichter durchzuführen.

Voraussetzung ist natürlich, daß man grundsätzliche Bedenken gegen die Zeitmessung mit Hilfe des $\mathrm{C}^{14}$-Zerfalls, wie sie im archäologischen Zusammenhang V. MrLojčıć (1957) ausführlich erörtert, innerhalb jungpleistozäner Zeiträume zurückstellen kann. Wie schwierig und unsicher die im üblichen Sinne archäologisch-chronologische Interpretation auch einer größeren Zahl von verfügbaren $\mathrm{C}^{14}$-Daten trotzdem noch bleibt - selbst wenn man die physikalische Methode als prinzipiell richtig voraussetzt -, haben den Verfasser eigene Erfahrungen (H. Müllek-Beck, H. Oeschger, U. Schwarz 1959) gelehrt. Vor übereilten Schlüssen auf Grund von Einzelmessungen ist unter allen Umständen zu warnen. Vor allem ist größte Vorsicht beim Gebrauch von $\mathrm{C}^{14}$-Daten am Platze, deren stratigraphische Bindungen an der Entnahmestelle nicht ausreichend publiziert worden sind. Diese Vorsicht ist besonders dann angebracht, wenn es um Größendifferenzen von weniger als 4-5000 Jahren (im älteren Jungpleistozän; im Neolithikum liegt der „kritische Bereich “ in archäologisch-chronologischer Hinsicht offenbar bei etwa 2-300 Jahren) geht. Bei Datierungen von paläolithischen Fundkomplexen ersetzt eine allgemeine Kulturbezeichnung genauere stratigraphische Angaben nur sehr unvollkommen. Im Bereich spät- 
altpaläolithischer Inventare dürften wegen der außerordentlich stark verzahnten typologischen Entwicklung sogar schwache stratigraphische Anhaltspunkte oft brauchbarer für die chronologische Einstufung sein als eine eingehende Publikation der vorhandenen Artefakte.

\section{B. Die terminologischen Grundlagen}

Die Begriffe „Riß/Würm-Interglazial“ und „Würm-Glazial“ gehen in ihrer nomenklatorischen Fassung auf A. PENCK \& E. BRüCKNEn (1901/09) zurück, die vor allem die würmzeitlichen Erscheinungen im Alpenraum - wegen ihrer naturgemäß guten Erhaltung - klar umschrieben. Schon in der abschließenden Zusammenfassung der „Alpen im Eiszeitalter" weisen sie darauf hin (S. 1159), daß die Lößbildungen wesentlich jünger sind als die typischen interglazialen Ablagerungen und bis in die Würm-Eiszeit hinein andauern. Es ergibt sich damit eindeutig ein klarer zeitlicher Abstand zwischen „typischem Interglazial" und "Würm" im alpinen Sinne. Im gleichen Zusammenhang wird auf das Erscheinen von Löß-Ablagerungen zwischen Riß- und Würm-Bildungen in den Ostalpen (detailliert Bd. I, S. 155) aufmerksam gemacht, eine stratigraphische Beobachtung, die Ursache vieler späterer Mißverständnisse werden sollte. Endlich wird (S. 1160) das Vorkommen geringmächtiger sporadischer Lößbildungen auf Würm-Ablagerungen angenommen. Die beobachteten interstadialen Phasen werden nur sehr zurïckhaltend behandelt und neben dem Hauptgeschehen als noch unbedingt untergeordnet angesehen.

Erst W. Soergel (1919) unterteilt auf Grund seiner durch J. BAyEr beeinflußten LößStudien die letzte Eiszeit in zwei Hauptabschnitte, deren ersten er vor das PENCK- BrüCKNER'sche Glazial (inkl. der folgenden "Hauptschwankung“ = "Göttweig“) einstufte. Den ersten Hauptvorstoß hält er zudem für den größeren von beiden. Noch in der Arbeit über die Ilm-Terrassen (1924) liegt der Hauptton ganz auf den beiden um die „Hauptschwankung" gruppierten Großgliedern. Erst unter dem Einfluß der von M. Milankovitch (1930) errechneten Strahlungskurve, deren Theorie dieser erst später ausführlich vorlegte (1941), hat W. Soergel seine Gliederung schließlich endgültig so dargestellt, wie sie nicht zuletzt gestützt durch die abstrakt-mathematische Autorität - im quartären Schrifttum weiteste Verbreitung fand. Besonders in der prähistorischen Literatur wurde sie ganz allgemein als Grundlage stratigraphischer Erörterungen und chronologischer Einstufungen benutzt (etwa L. F. Zotz 1951, S. 277). Das „Würm I“ um 110000 v. heute wird mit dem Eisvorstoß des norddeutschen Warthe gleichgesetzt. Dem folgenden W I/II-Interstadial werden „interglaziale, ja hoch-interglaziale Verhältnisse“ zugeschrieben, während „Würm II" (Weichsel) und „Würm III" nur durch ein kleines Interstadial getrennt erscheinen. „W I" zeigt in Norddeutschland einen Eisvorstoß bis $51^{\circ}$, "W II" einen solchen bis zu $52^{\circ}$ und "W III" endlich bis zu $53^{\circ}$ nördlicher Breite. Das „Riß/Würm-Interglazial“ wird auf eine Zeitspanne von knapp 10000 Jahren zusammengepreßt, auf der anderen Seite wird der Beginn des Aurignaciens auf etwa 80-70000 Jahre vor heute hinabdatiert.

\section{Hauptzüge der gegenwärtigen Diskussion}

Schon A. Penck hat der von W. Soergel eingeführten Gliederung in einer ganzen Anzahl von Arbeiten, auch unter Beiziehung archäologischer Argumente (A. PENCK 1938), widersprochen. Vor allem der ausstehende überzeugende Nachweis eines "Würm I“ SoErgeLscher Terminologie im alpinen Raum bestärkte seine Haltung. Mit Sicherheit (P. Woldstedt 1954) sind dagegen heute die Spuren der Warthe-Vereisung Norddeutschlands vor das letzte Interglazial (Eem) zu stellen. Damit fehlt aber ein direkter glazialmorphologischer Beleg für ein "Würm I“ im Sinne W. Soergel's in ganz Mitteleuropa. Die vorhandenen jungpleistozänen Moränen dürften sowohl in Norddeutschland (P. Woldstedt 1958 a, b), wie auch in den Alpen (A. Penck \& E. Brückner 1901/09, H. GRAUL 1955) in einen relativ späten Abschnitt des Jungpleistozäns gehören, der etwa 
dem Ausgang des Mittelwürms P. Woldstedt's entsprechen würde. Die glazialmorphologischen Belege der jungpleistozänen Klimaschwankungen bleiben also praktisch auf denselben Umfang beschränkt, der bei der ersten Einführung des Terminus „Würm“ zur Verfügung stand (s. a. S. 6).

Sehr viel unübersichtlicher liegen die Dinge in Bezug auf die schottermorphologische Gliederung der jungpleistozänen Terrassenbildungen. Es ist durchaus denkbar, daß sich auch vor dem klassischen „Würm“ im engeren Sinne Penck \& Brückner’s, vor allem im Bereich gletscherunabhängiger Fluß-Systeme, Schotterakkumulationen nachweisen lassen. $\mathrm{Daß}$ dies aber nur bei sorgfältigster Geländearbeit möglich sein wird, unterliegt kaum einem Zweifel. Wie schwierig auch selbst dann die Interpretation der Ergebnisse bleibt, zeigt etwa die ausführliche Diskussion von H. Graul und I. Schaefer (1953) im Illergebiet. Immerhin gibt es aber doch auch schottermorphologische Kriterien, die eine Umdeutung, wie H. Gross (1958) sie an der Jungriß-Auffassung J. BüDEL’s (1950) und F. Weidenbach's (1952) versucht, indem er den ganzen Komplex in sein „Würm I Altwürm" übernimmt, einigermaßen unwahrscheinlich machen. Auf Grund der Beweisführung der genannten Autoren, wie auch derjenigen von H. Graul (1955), wird man das alpine "Jungriß" - unbeschadet der etwas unglücklichen Diskussion von F. WeIDENвАсн (1956) - wohl am ehesten als Parallelerscheinung zum norddeutschen Warthe auffassen dürfen.

Erhebliche Fortschritte hat die jungpleistozäne Stratigraphie gerade in Mitteleuropa vor allem der neueren Löß-Forschung zu verdanken. Anstoß zur intensiveren Beschäftigung mit den Lössen gab nach dem Krieg vor allem H. Freising - ein Schüler J. BAYER's mit seinen detailreichen Arbeiten über die südwestdeutschen Lösse (kurz zusammenfassend: H. Freising 1956). Stärker pedologisch ausgerichtete Arbeiten führten die gegebenen Ansätze weiter, so in Bayern K. Brunnacker $(1953,1957)$, in Osterreich vor allem J. FinK (1956) und Fr. Brandtner (1956). Sehr zahlreich sind die löß-stratigraphischen Arbeiten im Gebiet der ČSR, von denen hier nur die weiterführende Zusammenfassung von Fr. ProšEk \& V. LožEK (1957) erwähnt sei. Eine ausgezeichnete Ergänzung in archäologischer Hinsicht bildet die Bearbeitung der fundreichen Lösse Nordwest-Frankreichs durch F. Bordes (1954), und, gleichsam als Brücke nach Mitteleuropa eingeschoben, die Publikation der Fundstelle von Achenheim durch P. WERNERT (1957). Die regionalen Einzeluntersuchungen zeigten eine durchaus uneinheitliche Gliederung des "Jüngeren Lösses“ in den verschiedenen Gebieten. Einer Dreiteilung in einzelnen Gebieten Osterreichs und der ČSR - aber auch Frankreichs, wenn auch hier in fazieller Modifikation - stand eine generelle Zweiteilung im Restgebiet Österreichs, in Süddeutschland und bei Achenheim gegenüber. Trotz verschiedener Umdeutungsversuche der regionalen Ergebnisse (Fr. Brandtner 1956, H. Gross 1957) ließ sich keine der beiden Auffassungen über das gesamte mitteleuropäische Lößgebiet ausdehnen. Eine Gesamtbearbeitung des süddeutschen Altpaläolithikums (H. MüLLER-BECK 1957 a) erbrachte keine klare stratigraphische Trennung interglazialer und W I/II-interstadialer (im Sinne SoERGEL's) Fundkomplexe im I.öß. Ganz generell fehlte in Süddeutschland auch periglazial jeder rechte Anhaltspunkt für ein „Würm I“ im Soergelschen Sinne. Die Trennung zwischen Interglazial und „Göttweig" blieb notgedrungen, wie P. Woldstedt (1958 c) in einer Besprechung mit Recht hervorhebt, unklar. Als Notlösung bot sich eine vorläufige Zusammenfassung dieser unübersichtlichen nachinterglazialen und vor- oder frühglazialen Phase unter der einfachen Bezeichnung „Übergangs-Abschnitt“ an. So ließ sich zugleich auch die Unmöglichkeit der vollständigen Interpretation der Vorgänge während dieses Zeitraumes mit Hilfe süddeutscher Belege allein am besten überbrücken. Ein Vergleich der Lößabfolgen und der in ihnen enthaltenen Artefakte zwischen Nordwest-Frankreich und Süddeutschland (F. BoRdes \& H. MüLLER-BECK 1956) ließen die besondere fazielle Empfindlichkeit der untersten Abschnitte des "Jüngeren Lösses“ offenkundig werden: drei in ihrem Aufbau 
relativ komplizierten „Jüngeren Lössen “ in Nordwest-Frankreich standen nur zwei in Süddeutschland gegenüber. Der „Würm I“-Löß trat in Süddeutschland in Zusammenhang mit Artefaktfunden offenbar überhaupt nicht auf. Schließlich gelang es K. BRUNNACKER (1957) durch Flächenkartierungen in den lößgünstigen Gebieten Südbayerns einen erhaltenen frühen „Jüngeren Löß“ nachzuweisen, den er seinem FWb (K. BRuNNACKER 1953, 1957) zuordnen konnte. Gleichzeitig zeigten stratigraphische Untersuchungen der LößSchnecken vor allem im Bereich der ČSR (Fr. ProšEK \& V. LožEK 1957, B. KLIMA 1957), daß Lößbildungen nicht nur in hocharktischen Phasen, sondern auch in noch klimagünstigen trockenen Abschnitten stattfinden konnten. So führen die beiden älteren Abschnitte der tschechischen Lösse noch relativ warme Schneckenfaunen; aber auch der Endabschnitt des obersten "Jüngeren Lösses" führt offenbar schon wieder empfindlichere Schnecken (B. KLIMA 1957). Daß jungpleistozäne Lößbildungen bei sogar noch günstigeren regionalen Temperaturverhältnissen vorkommen dürften, zeigt die Bearbeitung von jungpleistozänen Löß-Schnecken im Bereich der rumänischen Schwarzmeerküste durch G. HAASE \& $\mathrm{H}$. RICHTER (1957).

Die zwischen den verschiedenen speziellen Arbeitsrichtungen aufbrechenden terminologischen Gegensätze versuchte P. Woldstedt (1958 a, b) mit einer begrifflichen Neufassung der jungpleistozänen Hauptabschnitte zu überbrücken. Er unterteilte die auf das letzte Interglazial (Eem) folgende Zeitspanne in stratigraphischer Anlehnung an SoERGEL in Frühwürm, Mittelwürm und Spätwürm. Dabei würde das Eem - wie aus der Stellung des "Göttweig" in der von Woldstedt (1958 a) gegebenen Klimakurve gefolgert werden darf -- nur den klimagünstigsten Abschnitt der ursprünglich ausgedehnteren InterglazialAuffassung (im Sinne des von A. Penck und E. Brückner eingeführten Begriffes) umfassen. Auch der obere Abschnitt der Kurve bringt - wie schon erwähnt - eine praktische Annäherung an die alte Auffassung des "Würm“ (PENCK \& Brückner), da sämtliche belegte norddeutsche Stadien erst in das späte Mittel- und folgende Spätwürm noch nach dem "Paudorfer Interstadial“ angesetzt werden. Möglicherweise dürfen die Funde der jüngeren Hamburger Kultur von Grömitz (A. Rust 1955) unter Geschiebemergel als Kriterium für das unerwartet geringe Alter dieser Gletscherstände angesehen werden. Die späte Stellung der Jungmoränen wie der folgenden Rückzugs-Stadien und der daraus folgernden relativen Einheitlichkeit des durch sie belegten. Geschehens deckt sich mit der immer wieder erfolgten Stellungnahme eines großen Teiles der im alpinen Gebiet tätigen Geomorphologen. Vor allem C. 'Troll $(1924,1956)$ hat diese Auffassung wiederholt vertreten. Weitgehend gleichartig sind die Ergebnisse einer Neubearbeitung des jungpleistozänen Reuß- und Linthgletschers durch R. Havrke (1958). Auch im Bereich des Aaregletschers gehören sehr wahrscheinlich alle erhaltenen End- und Seitenmoränen dem erst späten - mit dem äußersten Rhonestand zusammenfallenden - Maximalvorstoß und den folgenden Rückzugsständen an. Die von P. BECK (1938) vorgelegten Verknüpfungen zwischen einem älteren - nur oberhalb von Belp nachweisbaren - Grundmoränen-Komplex und den hochgelegenen Seitenmoränen des jungpleistozänen Gletschers haben sich nicht verifizieren lassen. Ob der hochglaziale Löß-Hiatus („Paudorf“) noch vor oder erst zwischen die älteren glazialmorphologisch faßbaren jungpleistozänen Spuren des Aaregletschers einzuordnen ist, bleibt vorläufig ungewiß.

\section{Archäologische Beobachtungen}

A. Die jungpleistozäne Stratigraphie in Nordwest-Frankreich Die bisher vollständigste archäologische jungpleistozäne Stratigraphie wurde durch F. Bordes (1954) im für die Paläolithforschung klassischen Lößgebiet Nordwest-Frankreichs erarbeitet. Über dem auf dem obersten „Alteren Löß“ entwickelten interglazialen Waldboden, der deutlich eine sekundäre diagenetische Veränderung unter einer veränderten Pflanzendecke (Prairieboden I. Bordes \& Müller-Beck 1956) crkennen läßt, folgt 
ein erster, bei offenbar nur relativ geringer Klimaverschlechterung abgelagerter Löß mit altpaläolithischen Inventaren. Dieser Löß ist im unteren Teil durch eine nach oben allmählich abnehmende Humusbeimengung gekennzeichnet. Der obere Abschnitt ist zwar weitgehend humusfrei, zeigt aber eine deutliche, schon während der Ablagerung erfolgte Verwitterung, die auf jahreszeitlich beschränkte Niederschlagszunahmen zurückgehen dürfte. Die auf diesen ersten "Jüngeren Löß" folgende Verlehmung aus der Zeit eines Löß-Hiatus wird nur relativ selten nachweisbar, da sie weitgehend der durch mächtige Fließerden belegten anschließenden Erosion zum Opfer gefallen ist. Auch der folgende zweite "Jüngere Löß" zeigt noch eine leichte durchgehende Verwitterung und bleibt ebenfalls mit spät-altpaläolithischen Inventaren verbunden. Erst der durch eine weitere Verlehmung ausgewiesene zweite Löß-Hiatus steht mit jungpaläolithischen Funden lokaler westeuropäischer Entwicklungsprovenienz (Périgordien) in Zusammenhang. Über diesem Hiatus schließt sich ein dritter, der oberste und letzte "Jüngere Löß“, an, der auch in Nordwest-Frankreich unter voll-kontinentalem Klima gebildet worden zu sein scheint und in seinen oberen Partien sporadische spätpaläolithische Funde aufweist.

\section{B. Paläolithische Leitstationen in Mitteleuropa}

\section{Weimar-Ehrings dorf}

Diese in archäologischer Hinsicht größte interglaziale Fundstelle Mitteleuropas überhaupt hat in der stratigraphischen Diskussion immer wieder eine bedeutsame Rolle gespielt. Im System SoergeL's nimmt der „Pariser“ zwischen den beiden gebankten Travertinen eine ausgesprochene Schlüsselstellung ein. Schon 1924 parallelisiert er ihn mit seiner ersten Vorstoßphase innerhalb des alten PENCK'schen Interglazials (dem späteren Würm I). PENCK (1938) sah dagegen im „Pariser“ eine lokal bedingte Materialumlagerung ohne irgendwelchen allgemeinen stratigraphischen Wert.

Auch heute noch entscheidet die Einschätzung des „Parisers“ über die Gesamtauffassung der Bildungsgeschichte der Ablagerungen von Weimar-Ehringsdorf. Eine neue sedimentologische Bearbeitung des Parisers durch E. W. Guenther (1958) deutet ihn als Produkt einer Klimaverschlechterung, die der Bearbeiter immerhin mit einem „Eisvorstoß innerhalb Skandinaviens“ parallelisieren möchte. Die durch H. ZEIssLER (1958) vorgelegten Mollusken sprechen für ein zwar trockenes, aber insgesamt doch noch günstigeres Lokalklima während der Bildungszeit des Parisers. Diese beiden auf den ersten Blick etwas gegensätzlichen Befunde werden verständlicher, wenn man die individuenarme Schneckenfauna des Parisers als Reliktfauna auffaßt. Ein Ausharren an sich empfindlicher Mollusken bei günstigen mikroklimatischen Bedingungen - wie sie das Ilmtal gegenüber der Umgebung heute noch bietet - ist auch bei einer Verkürzung des Sommers während einer sogar relativ strengen Klimaverschlechterung denkbar. Umso mehr, als man sich in Mitteleuropa eine Klimaverschlechterung als Zunahme und Ausdehnung der kontinentalen Klimakomponente mit zwar kalten und trockenen Wintern, aber zunächst sicher kurzen, doch warmen und trockenen Sommern vorstellen kann. Auch die Lößbildung unter gleichzeitiger Anwesenheit von relativ empfindlichen Mollusken (Fr. ProšEK \& V. LožEK 1957) in den beiden unteren "Jüngeren Lössen“ der ČSR ist kaum anders als durch eine lange, anhaltende Kontinentalität des Klimas, die wohl noch über lange Zeit kaum als arktisch zu bezeichnen sein dürfte, zu erklären.

Wie groß die Klimaverschlechterung in der Bildungszeit des Parisers war, läßt sich - vor allem wegen des Fehlens eines klaren Beziehungsmaßstabes - gegenwärtig nicht übersehen. Die Fauna im Oberen Travertin und im Pariser (H.-D. KAHLKE 1958) zeigt jedenfalls eindeutig, daß wir mit dem Pariser das durch die Antiquusfauna gekennzeichnete Voll-Interglazial verlassen haben. Stratigraphisch ist der Pariser von WeimarEhringsdorf sicher eindeutig unmittelbar über dem Voll-Interglazial einzureihen. Unklar bleibt aber, ob und vor allem mit welcher älteren Phase der "Jüngeren Lösse“ er in Zu- 
sammenhang gebracht werden darf. Ein Ưrteil darüber wird erst möglich sein, wenn man die sehr wahrscheinlich außerordentlich schwankungsreiche Entwicklungsgeschichte der frühen "Jüngeren Lösse" in den verschiedenen Gebieten in ihrer unterschiedlichen faziellen Ausprägung vollständig kennt.

Die in Weimar-Ehringsdorf gefundenen Artefakte zeigen - wie wegen ihrer stratigraphisch-räumlichen Isolierung auch nicht anders zu erwarten - ausgeprägte Sonderzüge. Generell gehören sie zwar dem späten Altpaläolithikum (Mittelpaläolithikum mancher Autoren) an, können aber vorläufig nicht klar in das - durch die „Erhaltungs-Auswahl“ an sich schon recht lückenhafte - typologisch-chorologische System eingeordnet werden.

2. Lebenstedt

Auch das hier gefundene Steingeräte-Inventar (A. TODE 1953) mit ziemlich starken Faustkeilanklängen läßt sich nur generell einem relativ späten Altpaläolithikum zuordnen. Genauere typologisch-stratigraphische Beziehungen sind wegen des Fehlens entsprechender Vergleichsfunde nicht nachzuweisen. Einen besonderen Akzent erhält das Inventar von Lebenstedt durch die stoßlanzenartigen Knochenspitzen aus Großtier-Rippen und eine kurze breit-kegelförmige Knochenspitze. Die kleine, insgesamt etwas plump wirkende Spitze darf wohl als bisher frühester Beleg einer zusammengesetzten Jagdwaffe angesehen werden, eine Geräteentwicklung, die im Bereich des spätesten Altpaläolithikums östlich des Rheins und allgemein endlich im Jungpaläolithikum ihre konsequente Fortsetzung findet.

Sowohl die mitgefundenen Tierreste (A. Kreinschmidt 1953), wie auch die starken Frosteinwirkungen auf den Fundhorizont und die unterlagernden Sande (F. Preul 1953) sprechen für ein vom Voll-Interglazial, wie es uns in Weimar-Ehringsdorf begegnete, sehr verschiedenes Klima. Die Sedimente des Fundhorizontes und ihr Hangendes sind nach F. Preul (1953) in die erodierte, mit Geschiebemergel der Saale-Hauptvereisung bedeckte Mittelterrasse eingeschachtelt und bilden zusammen den Körper einer örtlich erhaltengebliebenen Niederterrasse. Eine kleinere Erosion im Hangenden der Fundschicht wird als möglicher Beleg einer Wärmeoszillation angesehen. Obwohl auf Grund der stratigraphischen Ergebnisse im Prinzip auch eine Einstuf ung der ganzen „Niederterrassen“Sedimente in die ausgehende mittelpleistozäne Vereisung oder das beginnende Interglazial möglich gewesen wäre, entschloß sich F. Prevl (1953) wie auch K. Richter (1953) für eine Einordnung in den Übergang zur jungpleistozänen Vergletscherung. Eine C ${ }^{14}$-Datierung der Fundschicht auf $48300 \pm 2000$ Jahre vor heute (GRO 1219, Hl. DE VRIEs 1958) bestätigt diese Ansetzung offensichtlich. Auf Grund der allgemeinen Beobachtungen im Bereich der Fundzone darf wohl angenommen werden, daß ihre Bildung relativ bald nach einer klimagünstigeren Phase erfolgte, also am ehesten als Zeugnis einer beginnenden Klimaverschlechterung angesehen werden darf. $\mathrm{Da}$ aber im Hinblick auf die faunistischen Reste in Lebenstedt kaum mit einer stratigraphischen Übereinstimmung mit der durch den Pariser in Ehringsdorf belegten Klimaverschlechterung zu rechnen ist - es sei denn, man würde ihm eine ausgedehnte Ausräumungsdiskordanz voranstellen -, würde in Lebenstedt bereits eine zweite auf das Voll-Interglazial folgende Klimaverschlechterung vorliegen. Klare Anhaltspunkte für eine Verbindung der Lebenstedt-Kaltphase mit einem der unteren "Jüngeren Lösse“ liegen gegenwärtig noch nicht vor. Die von F. Preul (1953) erwähnte - möglicherweise einer Wärmeoszillation angehörende - Erosion im Hangenden der Fundschicht könnte schon relativ bald nach der durch die Fundzone selbst belegten Kaltphase stattgefunden haben.

\section{Willendorf}

Vor allem die beiden Hauptstationen dieses Fundplatzes sind immer wieder als Ausgangspunkte für die Diskussion über die jungpleistozäne Stratigraphie des Paläolithikums, ja für die Gliederung des Jungpleistozäns ïberhaupt herangezogen worden. Die Gleich- 
setzung des „Göttweiger Interstadials“ mit der „Aurignac-Schwankung“ geht praktisch auf diese Fundstellen, vor allem Willendorf II, zurück. Die Stratigraphie von Willendorf II (H. Obermaier 1913, S. 291) mit dem insgesamt 18-20 m hohen Profil ist relativ einfach: Uber Schottern ein erster Löß, der von einer Verlehmung abgedeckt wird, darüber verlagerte Lehme und ein zweiter Löß. Die Funde (insgesamt 9 Horizonte) verteilten sich über die umgelagerten Lehme und den unteren Abschnitt des reinen oberen Lösses. Festzuhalten ist, daß aus der Verlehmung selbst, die ganz allgemein in das „Würm I/II Interstadial“ bzw. „Göttweig“ gesetzt wird (L. F. Zotz 1951, H. Gross 1956-1958), keine Funde vorliegen. Merkwürdig ist aber, daß auch die Fundhorizonte genau zu generell der gleichen Klimaphase zugeordnet werden. Die Bildung von Fließerden - in denen die Funde samt Begleitfauna eingebettet wurden — setzt zumindest periglaziales Bodenfließen voraus, also ein durchaus schon „post-interstadiales“ Klima. Die Größe des Sedimentationshiatus zwischen der Verlehmung und dem untersten Fließlehm-Horizont ist vollständig ungewiß. Das heißt aber, daß die stratigraphischen Verhältnisse in der Hauptfundstelle von Willendorf äußerst schwer zu beurteilen sind. Es könnte zum Beispiel eben so gut möglich sein,daß der unterste Lehm aus der "Laimenzone“ nicht mit "Göttweig“ im stratigraphischen Sinne SoERGEL's zusammengehört, sondern den Rest einer älteren Bodenbildung darstellt. Die Fließerden im Hangenden und der „unreine Löß“ können sowohl Umlagerungsprodukte dieser älteren Bodenbildung, wie auch späterer Verlehmungen in den unteren "Jüngeren Lössen" sein. Es ist nicht einmal ausgeschlossen, daß die oberen Fundstraten bis in den Zcitraum des „Paudorf“ (H. Gross 1958) hinaufreichen. Der L.öß unter der „Laimenzone“ ist jedenfalls bisher weder durch Artefakt-, noch durch Fossilfunde irgendwie zeitlich näher bestimmbar.

Sind schon die rein sedimentologischen Verhältnisse des Fundplatzes derart unglücklich, so gilt dies noch mehr für die typologisch-stratigraphischen Erscheinungen, die bis auf den heutigen Tag nicht einmal in ihren Hauptzügen publiziert wurden. Ob die untersten drei Fundhorizonte überhaupt schon als typisches Aurignacien im Sinne der gebräuchlichsten Typologie angesprochen werden dürfen, is völlig ungewiß. Erst in der 4. Fundzone treten offenbar Knochenspitzen mit gespaltener Basis auf, die wenigstens eine etwaige Gleichzeitigkeit mit dem typischen Aurignacien belegen. Selbst das wichtige Inventar dieser Fundzone ist bisher unpubliziert geblieben. Eine Holzkohlenprobe aus dem Fundhorizont 4 wurde auf $31840 \pm 250$ Jahre vor heute (GRO 1273, Hl. DE VRIEs 1958) datiert. Gerade bei der Auswertung dieser Altersangabe für die Vollgliederung ist Vorsicht geboten. Es ist durchaus möglich - und scheint im Vergleich mit anderen Fundstellen, wie wir noch sehen werden, sogar wahrscheinlicher - , daß der Fundhorizont 4 keineswegs mehr einem klimagünstigen Abschnitt, sondern schon einer relativ ungünstigen Klimaphase angehört. Abschließend bleibt zu sagen, daß den Fundpunkten um Willendorf erst dann wirklich ein Gewicht in der allgemeinen Diskussion zugemessen werden kann, wenn das Fundmaterial zuverlässig publiziert vorliegt.

4. A chenheim

Erheblich glücklicher liegen die Verhältnisse, dank der sich über mehr als 50 Jahre erstreckenden Sammeltätigkeit P. WERnERT's und seiner jetz.t vorliegenden Monographie (P. Wernert 1957), in Achenheim. Vor allem läßt sich hier jetzt die stratigraphische Stellung des "Aurignacien typique“ (Aurignacien moyen BreuIL's) im Löß eindeutig fixieren.

Auch hier ist der Aufbau der Stratigraphie der "Jüngeren Lösse“ relativ einfach (Abb. 1): Uber der umgelagerten Verlehmungszone der "Alteren Lösse“, die hier sowohl durch Artefakte wie Fossilkunde klar gekennzeichnet sind, folgen zwei durch eine Fließlehm-Zone getrennte "Jüngere Lösse“. Etwa in der Mitte des ersten "Jüngeren Löß" von Achenheim traten wiederholt Steingeräte des "Aurignacien moyen " (Aurignacien typique") auf, im Bereich der Fließlehme an der Basis des zweiten "Jüngeren Löß“ fanden sich Artefakte des „Aurignacien final“ (P. WERnERT 1957). 

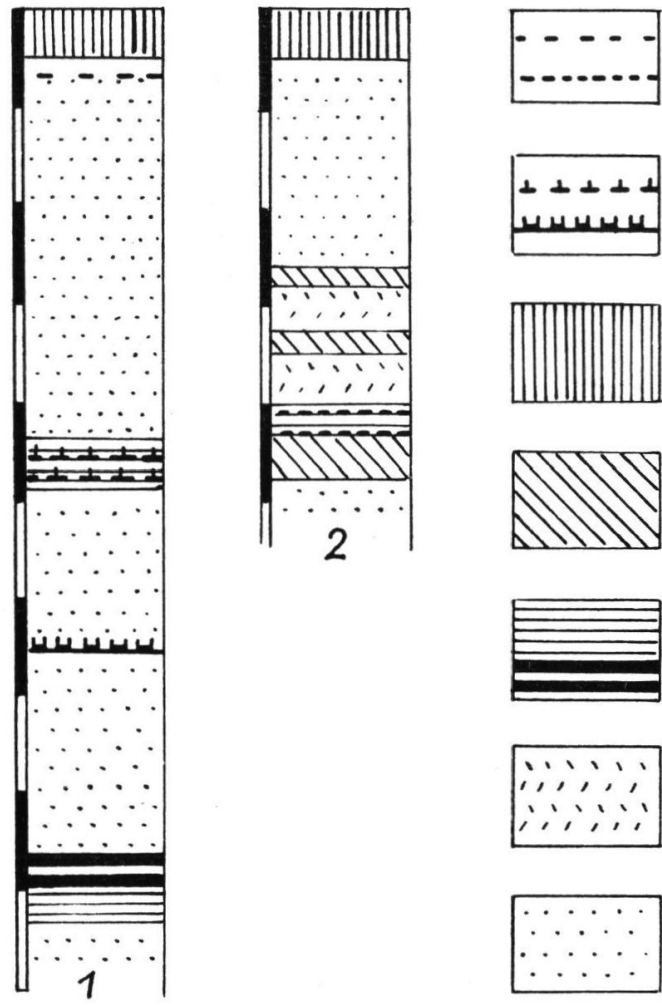

Spätjungpaläolithikum

Ostgravettien

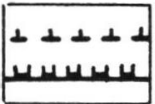

Spätaurignacien

Aurignacien typique

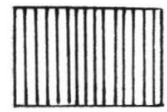

Rezente Bodenbildung

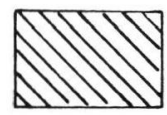

Anstehende fossile Lehme

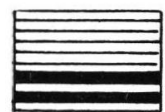

Umgelagerte fossile Lehme

Moustéroides Altpaläolithikum

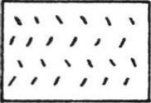

Vergleyungshorizonte

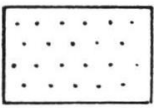

Löß

Abb. 1. Profilabfolge von Achenheim (1), oberer Abschnitt, nach P. WERnERT (1957), und UnterWisternitz (2), oberer Abschnitt, nach B. KLímA (1957). Maßstababschnitt: 1,0 m.

Damit läßt sich aber die stratigraphische Stellung des typischen Aurignacien in diesem Profil auch verallgemeinernd bestimmen. Die verflossenen Lehme über dem „Älteren Löß“ schließen - wie etwa in den süddeutschen Normalprofilen - die auf das Voll-Interglazial folgenden Klimaschwankungen mit ein. Die oberen, die beiden „Jüngeren Lösse“ trennenden verflossenen Lehme präsentieren den in ganz Europa nachweisbaren vollglazialen LößHiatus mit subarktischem Klima im größten Teil Mitteleuropas. Eine Gleichsetzung dieser Zone mit dem „Göttweig “ im Sinne SoergeL's ist ausgeschlossen, da sonst eine Ansetzung des typischen Aurignacien noch vor diesem Abschnitt nicht zu umgehen wäre. Sieht man diesen Ausweg aber als gesperrt an, so wäre damit der Beweis der Möglichkeit eines Ausfalles der frühen Sedimentationsabschnitte des "Jüngeren Lösses" erbracht. Regional können also durchaus nur die beiden oberen "Jüngeren Lösse“ auftreten, so wie wir das schon in anderem Zusammenhang (F. Bordes \& H. MüLLER-BECK 1956) für möglich hielten. Durch Spuren eines späten Jungpaläolithikums im obersten "Jüngeren Löß“ dicht unter der holozänen Bodenbildung wird diese Auffassung weiterhin gestützt.

\section{Ste t ten-Vogelherd}

Das Stein- und Knochengeräte-Inventar aus den Fundhorizonten V und IV des Vogelherdes steht in relativer Nähe des ältesten jungpaläolithischen Fundkomplexes von Achenheim. Darüber hinaus können die Funde aus dem Horizont V (G. RIEK 1934) als gerade$\mathrm{zu}$ hervorragend kennzeichnend für das „Aurignacien moyen “ (Aurignacien typique) angesehen werden. Bereits G. RIEK (1934) hat beide Horizonte in das „Würm I/II-Interstadial“ im Sinne Soergel's datiert, eine Einstufung, die mit dem lößstratigraphischen 
Befund von Achenheim offenbar im Widerspruch steht. Auch der Befund von Willendorf würde bei allen Schwierigkeiten und Unklarheiten nur mühsam damit in Einklang zu bringen sein.

Auf der anderen Seite sind die Höhlensedimente während der beiden AurignacienBegehungen unter einigermaßen günstigen klimatischen Bedingungen abgelagert worden, die, relativ genommen, sicher besser waren, als in den folgenden Schutthorizonten. Ein absoluter Gradmesser für die Klimaverhältnisse fehlt dagegen sowohl 'in den Aurignacien- wie in den höheren Horizonten. Dieses noch relativ günstige Klima während der Schuttbildung der Horizonte V und IV kann dennoch durchaus mit den Vorgängen in Achenheim und ihren Aussagen in Einklang stehen. Wie schon mehrfach erwähnt, scheint das Klima zur Zeit der Sedimentation des mittleren Abschnittes der "Jüngeren Lösse“ relativ günstig gewesen zu sein, während erst das Klima zur Zeit der Ablagerung der obersten "Jüngeren Lösse" die extremsten Werte zu erreichen scheint. Auch an dieser Stelle sei noch einmal ausdrücklich vor einer Überschätzung des Lösses als Temperatur-Indikator gewarnt. Selbst relativ warme, aber trockene Klimaabschnitte werden ihn eher begünstigen als kühlere, aber feuchte.

Wenn auch hier nicht auf die Problematik der Klima-Aussagen von Höhlensedimenten eingegangen werden soll, so sei doch auf die Schwierigkeiten hingewiesen, die ganz allgemein einem Vergleich zwischen ihnen und - vor allem relativ kurz dauernden - LößSedimentationen begegnen dürften. Auch der Befund der Istállóskö-Höhle (L. VéRTES 1955) zeigt dies deutlich. Das dortige etwas unglücklich als „Aurignacien I“ bezeichnete Inventar, das besser als spätaltpaläolithische Parallelerscheinung zum „typischen Aurignacien" aufzufassen ist, wurde von L. VÉRTEs in den B e g in $\mathrm{n}$ eines lang andauernden Interstadials gesetz.t. Als Datum für diese Begehung ermittelten L. VÉRTEs und Mitarbeiter (1955) etwa 110000 Jahre vor heute. Eine C14-Datierung (GRO 1501, Hl. DE VRIEs 1958) ergab hingegen $30670 \pm 500$, ein Datum, das H. Gross (1958) etwa als das En de des "Göttweiger Interstadials“ annehmen möchte.

Wir werden in unseren Schlußfolgerungen auf dieses Problem noch einmal zurückkommen. Gestützt auf den Befund von Achenheim, wollen wir aber vorläufig festhalten, daß das Aurignacien aus dem Horizont V des Vogelherdes am ehesten mit der Ablagerung des mittleren Abschnittes des "Jüngeren Lösses“ zu parallelisieren ist. Das Aurignacien aus dem Horizont IV mag hingegen schon dem folgenden Löß-Hiatus angehören.

6. Unter-Wisternitz

Ein klarer typologischer und stratigraphischer Befund liegt von dieser Station (B. KLIMA 1957) vor. Uber einer späten Bodenbildung im Löß, bzw. im Bereich eines anschließenden Umlagerungshorizontes (G 1) wurden außerordentlich zahlreiche Spuren eines östlichen Gravettien im unteren Bereich des letzten „Jüngeren Lösses“ angetroffen, ein Befund, der mit den Beobachtungen P. Wernert's (1957) in Achenheim und der dortigen Stellung des „Aurignacien final“ in etwa übereinstimmt (Abb. 1).

Das Gravettien von Unter-Wisternitz gehört am ehesten dem Ausgang des Unterbruches des "Paudorfer Sedimentationshiatus“ und der wieder beginnenden Löß-Anwehung an, die trotz Abnahme der Niederschläge regional zunächst noch durch Umlagerungen stark überprägt erscheint. Im Zusammenhang mit den Versuchen einer jungpleistozänen Vollgliederung - die auch die Verknüpfung der Lößbildung mit jener der Gletscher erfordern würde - ist auf die Schwierigkeiten zu verweisen, die bei derartigen einfachen Gleichsetzungen, wie sie im allgemeinen noch üblich sind, a priori auftreten. Die Verhältnisse sind wahrscheinlich noch komplizierter, als sie B. KLIMA (1957) für den Beginn seines W 3 darstellt. Geht man davon aus, daß der Löß unter ve r s c h i e d e n e n $\mathrm{kl}$ i mat is chen B ed ing ungen, aber nur bei relativer Trockenheit zur Ablagerung gelangen kann, so ergibt sich etwa folgender Zusammenhang zwischen Löß- und Gletscherbildungen im Bereich eines voll-glazialen Interstadials (Abb. 2): 
1. Lößanwehung zur Zeit der kältebedingten Trockenheit, in der nur noch ein geringer absoluter Gletscherzuwachs stattfindet.

2. Bei beginnender Erwärmung im Zuge einer Klimaoszillation zunächst noch trockene kühle Winter, aber wärmere Sommer mit zunehmender Schmelzwirkung. Anhalten der Lößbildung, aber schon deutlicher Gletscherschwund und Rückzug des Eises, der sich ständig beschleunigt.

3. Im Anhalten der Oszillation Schwächung der kontinentalen Komponente; wärmere, aber feuchte Winter; feuchtere, aber etwas kühlere Sommer. Die Lößbildung setzt aus, der Gletscherschwund läßt allmählich nach, der Eisrückzug verlagsamt sich, Ende des glazialmorphologischen "Interstadials“.

4. Wiederabkühlung bei noch relativ starker atlantischer Komponente, kühle feuchte Sommer und Winter. Anwachsen der Gletscher mit hohen Jahresraten, keine Lößbildung, allmähliches Einsetzen des periglazialen Bodenfließens (Tundra-Phase B. KLIMA's beginnt).

5. Erreichung kontinentaler Bedingungen, trockene kalte Winter, kurze warme Sommer. Nachlassen des Gletscherzuwachses, Neubildung von Löß.

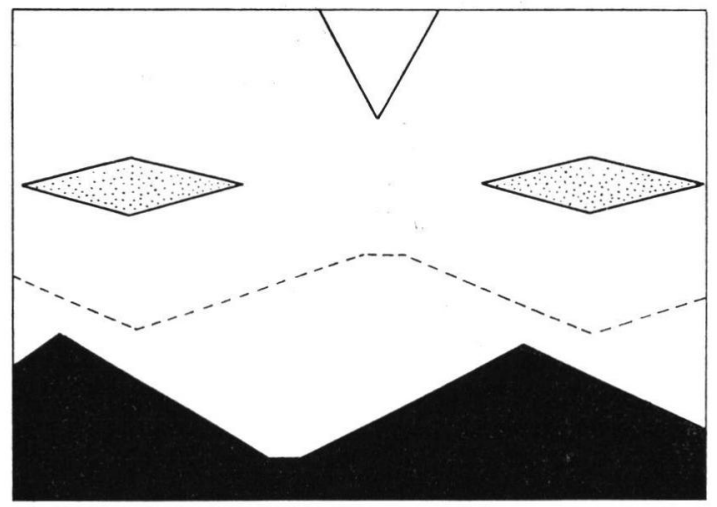

Abb. 2. Schematische Darstellung der Beziehungen der Hauptklimakomponenten, Lößbildung und Gletscherzuwachs. Schwarze Fläche: Temperaturschema, Gang von einem Kältemaximum über eine Wärmeoszillation zu einem zweiten Kältemaximum; Gestrichelte Linie: Niederschlagschema, Gang von einem Niederschlagminimum über ein Maximum zu einem zweiten Minimum; Punktrhomben: Phasen der Lößbildung mit Maximum bei der senkrechten Achse; Hängendes Dreieck: Bereich des Haupt-Gletscherzuwachses.

Damit darf man aber annehmen, daß neben den Mikrozyklen, die B. KLIMA (1957) nachweisen kann, auch im Bereich einer größeren Oszillation - wie sie das „Paudorfer Interstadial" (P. WoLDSTEDT 1958 a) etwa darstellen würde - ganz erhebliche Verschiebungen zwischen echten Glazial-Interstadialen und Sedimentationsunterbrüchen im Löß auftreten können. Die Synchronisation zwischen Löß- und Glazialbildungen wird dadurch nicht unwesentlich noch zusätzlich erschwert. Konkret ausgedrückt, kann zwischen zwei Lößbildungsphasen (Abb. 2) ein erheblicher Hiatus liegen, der, klimatisch gesehen, nur die Endphase einer Wärmeoszillation und $\mathrm{noch}$ vor Einsetzen des nachweisbaren periglazialen Bodenfließens größere Abschnitte einer beginnenden Klimaverschlechterung umfassen würde. Es wäre vielleicht angebracht, um Mißverständnisse auszuschließen, den Terminus „Interstadial“ besser nicht auf Lößbildungslücken anzuwenden, sondern wenn man nicht von „Bodenbildungszeit" sprechen will - lieber den Begriff „Löß-Hiatus“ einzuführen. Praktisch bedeutet das einerseits, daß eine Station wie Unter-Wisternitz, für die auf Grund älterer Proben ein C14-Datum von $25600 \pm 170$ Jahren (GRO 1286, Hl. DE VRIEs 1958) angegeben wird, zeitlich erst relativ spät auf den Höhepunkt der vorhergehenden Wärmeoszillation folgen kann, die im Gletscherbereich unmittelbar wirksam 
ist, dort also in absolut älter zu datierenden Sedimenten erscheinen würde. Möglicherweise können die Torfe des Karrestobels (Hl. DE VRIES 1958) um 29-28000 vor heute mit ihr in Zusammenhang gebracht werden.

7. Pollau

Ahnlich eindeutig wie in Unter-Wisternitz liegen die stratigraphischen und typologischen Verhältnisse in Pollau. Auch diese fundreiche Station liegt im Beginn der Ablagerung des obersten "Jüingeren Lösses", etwas später als die eben behandelte Station von Unter-Wisternitz (B. KLIMA 1957). Von den beiden bisher für diese Station zur Verfügung stehenden $C^{14}$-Daten (GRO 1272 und GRO 1325, H1. DE VRIEs 1958) stimmt die Datierung mit $24800 \pm 150$ Jahren vor heute gut mit dieser Auffassung ïberein. Die Altersangabe $26400 \pm 230$ (GRO 1272), die Hl. DE VRIEs (1958) mit der möglichen Beimischung fossiler Kohle zu erklären sucht, würde dem von B. KLIMA angegebenen Verhältnis widersprechen.

\section{Stratigraphische Folgerungen in Mitteleuropa}

Vom Standpunkt des Archäologen aus darf die stratigraphische Fixierung des jungpleistozänen Voll-Interglazials trotz der völlig mangelhaften typologischen Anknüpfungsmöglichkeiten als ausreichend gelten. Der Untere Travertin von Ehringsdorf mit der in ihm enthaltenen Antiquusfauna kann im mitteleuropäischen Bereich als Typus-Lokalität angesehen werden. Die untere stratigraphische Begrenzung dieses Voll-Interglazials ist allerdings noch unklar (s. H.-D. KAHLKE 1958). Die obere stratigraphische Begrenzung wird dagegen durch den wahrscheinlich schon klimaungünstigeren "Pariser“ dargestellt, ïber dem bereits die Primigeniusfauna des Jungpleistozäns folgt.

Weniger klar umreißbar sind die folgenden stratigraphischen Abschnitte. Der Pariser selbst darf wohl als Beleg einer Klimaverschlechterung, wenn auch unbekannten Ausmaßes, bei zunehmender Trockenheit angesehen werden. Der Obere Travertin zeigt zwar in der Gesamtheit wieder eine Klimabesserung an, bleibt aber - wie die Faunenfolge in ihm belegt - insgesamt doch unter den Bedingungen des Voll-Interglazials. Der „Pseudopariser" im Oberen Travertin kann möglicherweise als Beleg für eine weitere relative Klimaverschlechterung angesehen werden. Die Verbindungen zwischen Unterem und Oberem Travertin sind trotz des durch den „Pariser“ gegebenen Einschnittes sedimentologisch derart eng, daß es angebracht sein dürfte, auch den Oberen Travertin und die durch den Pariser angezeigte Kälteoszillation noch als Spätphase dem Interglazial zuzurechnen. Eine Verbindung zwischen einem frühen „Jüngeren I.öß“ und dem Pariser läßt sich vorläufig nicht nachweisen.

Eine weitere Kälteoszillation scheint die Fundstelle von Lebenstedt anzuzeigen, auf die möglicherweise eine etwas geringere Wärmeschwankung folgt. Ob das Profil von Lebenstedt im „Pseudopariser" von Ehringsdorf oder in der dort in Hangenden folgenden großen Erosionsphase einen Anknïpfungspunkt besitzt, ist vorerst ungewiß. Terminologisch dürfte es vertretbar sein, Lebenstedt schon dem eigentlichen Frühglazial zuzurechnen. Die folgenden, ebenfalls kaum einphasigen Schwankungen dürften wohl dem Frühglazial K. Brunnacker's (1953) und dem Frühwürm P. Woldstedt's (1958 a u. b) in etwa entsprechen.

Um die stratigraphischen Unklarheiten und die klimatologische Zwitterstellung des ausgehenden Interglazials und des folgenden frühen Glazials zu betonen, werden in der beigegebenen Übersicht (Abb. 3) beide Abschnitte zusammenfassend als A n a gla zial bezeichnet. Wir verstehen darunter den Übergangsbereich zwischen Voll-Interglazial und Voll-Glazial, der bei ständig zunehmender absoluter Klimaverschlechterung durch die besondere sedimentologische Wirksamkeit der Temperatur- und Niederschlagsoszillationen gekennzeichnet wird. Weiterhin ist diese Phase durch die allmähliche Ablösung des zunächst weitgehend atlantischen Klimas durch kontinentale Komponenten in ganz Mittel- 


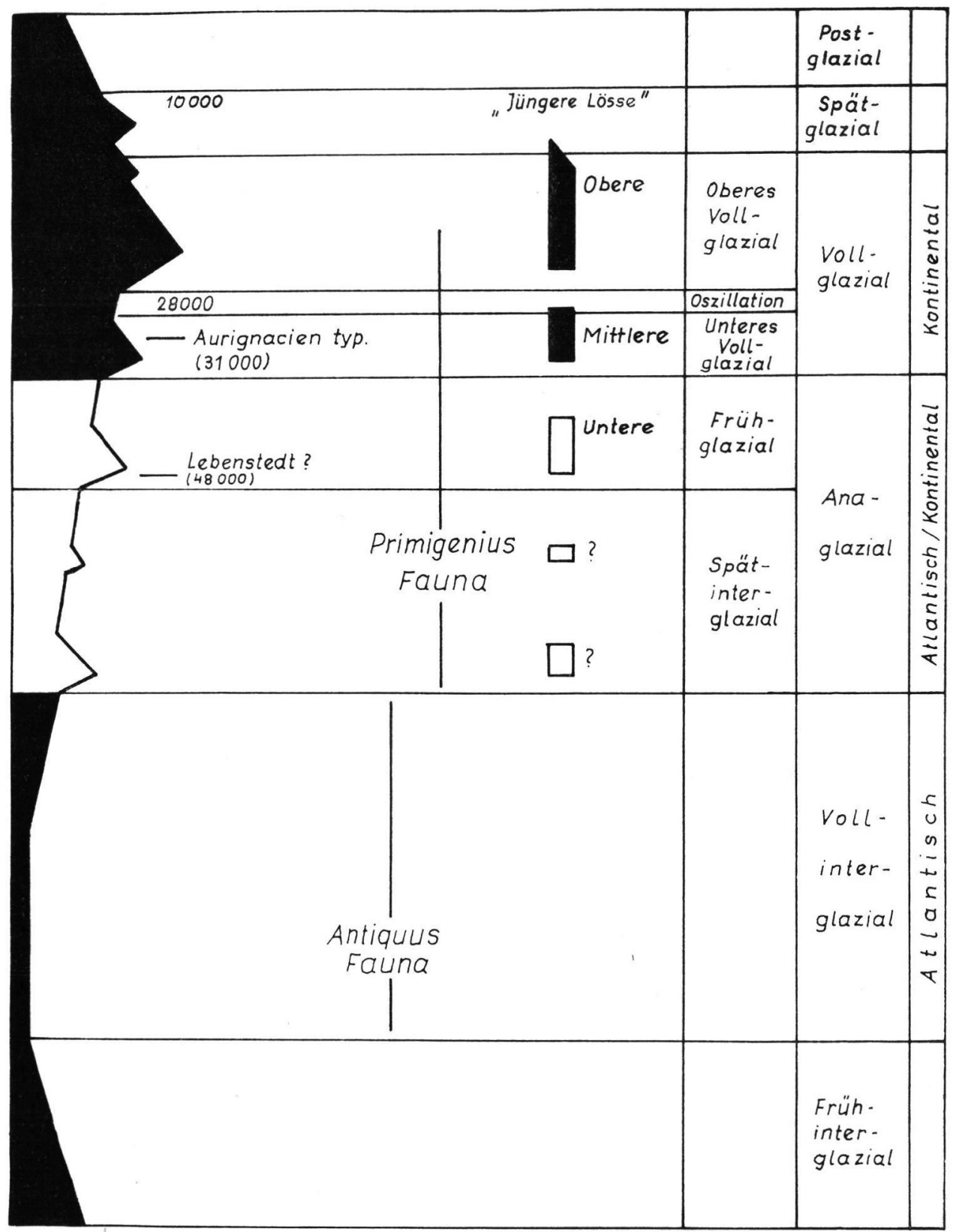

Abb. 3. Hauptabschnitte der jungpleistozänen Klimaentwicklung in Mitteleuropa. Schwarze Fläche: Temperaturschema, Ablauf in etwa gesichert; unausgefüllte Fläche: im Ablauf noch ungesicherte Abschnitte der anaglazialen Temperaturentwicklung. Die Temperaturveränderungen sind relativ zum Temperaturniveau des Voll-Interglazials wiedergegeben. Die eingefügten Zeitangaben sind nur annähernd maßstäblich eingetragen, wie der Darstellung überhaupt $\mathrm{k}$ e in e in h e i t l i c h e r $\mathrm{Z}$ e i t m a ß s a b zu Grunde liegt. Nur das Obere Voll-Glazial dürfte dem klassischen "Würm“ (PENCK) entsprechen. Die äußerste rechte Spalte gibt den hauptsächlichen Klimacharakter des zugehörigen Abschnittes an; vor allem die jeweiligen, dem hauptsächlichen Klimacharakter entgegengesetzten Oszillationen werden als stratigraphische Marken erkennbar: Kontinentale Oszillation im sonst noch atlantischen Anaglazial als "Pariser", atlantische Oszillation im sonst kontinentalen Voll-Glazial als voll-glazialer Löß-Hiatus etc. 
europa bestimmt. Die Winter werden mit der Zeit bedeutend strenger, während die Sommer zwar allmählich kürzer werden, aber relativ warm bleiben dürften. In länger anhaltenden trockenen Perioden ist Lößbildung trotz einer noch relativ günstigen jährlichen Temperatursumme (begünstigt in lokalen Trockengebieten) möglich. Die untersten "Jüngeren Lösse" dürften dem Anaglazial angehören. Für das Verhalten der Gletscher während des Anaglazials fehlen in Mitteleuropa sämtliche Anhaltspunkte. Es ist immerhin denkbar, daß die nordeuropäischen und nordamerikanischen Eiskappen schon während des Anaglazials eine bedeutende Zunahme aufweisen, dürften sie doch auf Temperaturabsenkungen unmittelbarer reagieren als die zunächst nur indirekt betroffenen europäischen und asiatischen Gebirgsgletscher. Hier dürfte die Eiszunahme erst in dem Moment größere Ausmaße erreichen, wo Temperaturabsenkungen mit Perioden stärkerer atlantischer Einflüsse zusammenfallen. Die frühe Lößbildung in Nordwest-Frankreich wäre im Falle einer subglazialen Flächenzunahme der zirkumpolaren Gletscher und entsprechender Absenkung des Meeresspiegels bei noch relativ günstigem Regionalklima in Europa unter Umständen überraschend einfach zu erklären. Man könnte diesen frühen küstennahen Löß als winterliches Ausblasungsprodukt der allmählich trocken fallenden Küstensäume und untermeerischen Mündungsdeltas auffassen.

Festeren Boden bekommen wir in stratigraphischer Hinsicht zur Zeit der Ablagerung des mittleren "Jüngeren Lösses" unter die Füße. Er steht durch den Befund von Achenheim eindeutig mit dem "Aurignacien typique" in Verbindung. Unserer Ansicht nach gehört das für die paläolithische Stratigraphie so bedeutsame echte Aurignacien in Mitteleuropa nicht mehr einer „interstadialen Schwankung“ („Göttweig“ H. Gross 1956) an, sondern steht eindeutig im folgenden Löß. Auch wenn dieser Löß ganz offensichtlich noch unter etwas besseren allgemeinen klimatischen Bedingungen abgelagert wurde als der oberste "Jüngere Löß“, läßt sich die Stellung des „Aurignacien typique mit Knochenspitzen mit gespaltener Basis“ im „Göttweig“ aus folgenden Gründen nicht halten:

1. liegen keine stichfesten Belege für ein typisches Aurignacien aus der dem "Göttweig“ zugeschriebenen Bodenbildung, bzw. an der Oberkante der vollständig erhaltenen Bodenbildung, vor. Selbst in Willendorf tritt echtes Aurignacien erst im Horizont 4 in Fließerden eingebettet über der "Laimenzone" auf. Auch die Zone 2 besitzt gegenüber der Bodenbildung im Liegenden einen erheblichen Abstand, einen noch größeren gegenüber dem tatsächlichen Maximum der zugehörigen Wärmeoszillation;

2. belegt Achenheim die Stellung des "Aurignacien typique“ im Löß einwandfrei;

3. kommt dazu, daß bisher für alle Inventare mit echtem Aurignacien, für die $\mathrm{C}^{14}$-Daten bekannt gegeben wurden, ein Alter von ca. 31000 Jahren genannt wird. Neuerdings wird das gleiche Datum für einen Löß in Ober-Fellabrunn (Hl. DE VRIEs 1959) angegeben, was mit der Beobachtung von Achenheim übereinstimmen würde.

Dadurch läßt sich aber gleichfalls wahrscheinlich machen, daß tatsächlich der noch mit Recht! - als klimagünstig interpretierte Sedimentabschnitt V des Vogelherdes schon mit einer neuen Lößbildung parallel läuft. Es zeigt sich damit zugleich eindeutig, mit welcher Vorsicht relative Klimamerkmale verschiedener Sedimente miteinander zu verbinden sind. Außerdem bleibt festzuhalten, daß, gestiitzt auf die oben zusammengefaßten stratigraphischen Beobachtungen, um 31000 vor heute von einem Löß-Hiatus, wie ihn das terminologisch ja im Löß fixierte "Göttweig" von H. Gross (1958) darstellen würde, keine Rede sein kann. Wir müssen den Beginn der Lößbildung wahrscheinlich sogar um eine nicht unerhebliche Zeitspanne früher ansetzen, den Höhepunkt der vorangehenden tatsächlichen Wärmeoszillation sogar bestimmt um einige Jahrtausende. Das heißt aber zugleich, daß wir uns auf Grund der zur Verfügung stehenden archäologischen und stratigraphischen Anhaltspunkte eher mit der in der Einführung erwähnten Auffassung von Hl. DE VRIEs $(1958,1959)$ einverstanden erklären müßten als mit jener von 
H. Gross (1958). Grundsätzlich glauben wir zudem, daß die jungpleistozäne Stratigraphie des mitteleuropäischen Paläolihtikums - dank des Befundes von Achenheim - vom Auftreten des "Aurignacien typique“ an in ihren Hauptzügen als geklärt angesehen werden darf.

Der folgende Löß-Hiatus rïckt damit relativ dicht an das "Aurignacien typique " heran, ebenso die darauf folgenden jungpaläolithischen Stationen der ČSR. Das Aurignacien des Horizontes IV des Vogelherdes fällt möglicherweise bereits in die dem Löß-Hiatus vorangehende und teilweise noch parallel laufende Wärme-Oszillation. Damit schrumpft aber der Abstand zwischen Vogelherd IV und Unter-Wisternitz noch weiter zusammen, und die bisher als merkwürdig angesehene, durch die Tierskulpturen beider Stationen belegte enge Beziehung, die L. F. Zotz (1951, S. 203) als vorläufig unerklärlich bezeichnete, wird verblüffend selbstverständlich.

In der beigegebenen Ubersicht (Abb. 3) wird die Bildungszeit der mittleren und oberen „Jüngeren Lösse“ einschließlich des dazwischen geschobenen Hiatus unter dem Begriff Voll-Glazial zusammengefaßt. Stratigraphisch wird das Voll-Glazial spätestens durch das Auftreten des typischen Aurignacien gegen das Anaglazial abgetrennt, bzw. soweit fixierbar, durch den Beginn der vorher liegenden stärkeren Klimaverschlechterung. Den oberen Abschluß des Voll-Glazials bildet der Beginn des Alleröd als Anfang des Spät-Glazials, das seinerseits in Mitteleuropa bis zum Ausgang der Jüngeren Dryas etwa 10000 Jahre vor heute reicht. Der Höhepunkt der Klimaverschlechterung liegt im Bereich des oberen „Jüngeren Lösses“, mit dem aller Wahrscheinlichkeit nach erst die erhaltenen jungpleistozänen Gletscherspuren des alpinen und nordeuropäischen Raumes $\mathrm{zu}$ verbinden sind.

\section{Schluß}

Die vorgelegten Beobachtungen und Überlegungen scheinen eine fast vollständige Abkehr von den Gliederungsvorstellungen SoEngeL's für das mitteleuropäische Jungpieistozän erforderlich zu machen. Es fehlt jeder periglaziale und glaziale Anhaltspunkt für eine tief akzentuierte zweiteilige Gliederung in seinem Sinne. Über dem Voll-Interglazial, wie es sich stratigraphisch in W'eimar-Ehringsdorf überzeugend fassen läßt, folgt eine schwankungsreiche - in sich noch nicht klar zu gliedernde -, sehr wahrscheinlich lang dauernde Übergangsphase. Wenn auch gelegentlich für kürzere Zeit relativ schlechte Temperaturverhältnisse während dieses Überganges geherrscht haben können, so geschieht die generelle Abkühlung doch nur allmählich. Unabhängig von der ständig fortschreitenden Temperatur-Erniedrigung läuft der Wechsel von trockneren und feuchten Perioden, die in Verbindung mit den langsam sich ändernden jährlichen Temperaturverhältnissen sehr unterschiedliche lokale Klimate hervorzurufen scheinen. Auch die voll-glaziale Oszillation (zwischen 30000 und 27000 vor heute) kann noch als Nachschlag dieses Überganges aufgefaßt werden. Es ist zu vermuten, daß der Hauptvorstoß der mitteleuropäischen Gletscher erst in den oberen Abschnitt des Voll-Glazials fällt. Damit ergäbe sich aber - trotz der eingeschobenen langen Übergangsphase - ein in sich sehr geschlossener glazialmorphologischer Komplex im Sinne der von PENCK \& BRÜCKNER vorgelegten Ergebnisse.

Terminologisch wäre es deshalb unbedingt konsequent, auch im prähistorischen Bereich auf die von SoERgEL geprägten Begriffe zu verzichten. Das gilt vor allem für die Bezeichnungen wie Würm I, Würm II, Würm III und "Göttweiger Interstadial“ = "Aurignac-Schwankung “. Es wäre besser, in Zukunft das Jungpleistozän etwa wie folgt zu unterteilen (Abb. 3):

Frïh-Interglazia 1

Voll-Interglazial

Spät-Interglazial mit spät-interglazialen Schwankungen 
Früh-Glazial mit früh-glazialen Schwankungen

Unteres Voll-Glazial

Voll-glaziale Schwankung

Oberes Voll-Glazial

$S$ pät-Glazial

Allenfalls könnte man für die beiden Abschnitte des Voll-Glazials die Begriffe W I und W II wieder benutzen (K. Brunnacken 1957), läuft dann aber Gefahr, Verwechslungen mit anderen älteren gleich bezeichneten Begriffen hervorzurufen. Wesentlich scheint uns bei der vorgeschlagenen Terminologie vor allem, daß die im Grunde - trotz aller Schwankungen - in einer großen Kurve verlaufende Klimaentwicklung bis zum „Kälte-Maximum“ im Oberen Voll-Glazial deutlich in Erscheinung tritt. Dabei ist allerdings zu beachten, daß dieses Maximum ein vorläufig auf Mitteleuropa beschränktes „Wirksamkeits-Maximum " ist. Es ist durchaus denkbar, daß in anderen Gegenden der Erde bei anderen voll-interglazialen klimatischen Ausgangsbedingungen andere Abfolgen der tatsächlichen Auswirkungen auftreten.

\section{Angeführte Schriften:}

Andersen, Sv. Th.: New Investigations of Interglacial Fresh-Water Deposits in Jutland. - Eisz. u. Geg. 8, 181-185, 1957.

BECK, P.: Studien über das Quartärklima im Lichte astronomischer Berechnungen. - Eclog. geol. Helv. 30, 241-262, 1937, 31, 137-172, 1938.

Bordes, F.: Les limons quaternaires du Bassin de la Seine. - Paris 1954.

Bondes, F. \& Müller-Beck, H.: Zur Chronologie der Lößsedimente in Nordfrankreich und Süddeutschland. - Germania 34, 199-208, 1956.

Brandtner, Fr.: Lößstratigraphie und paläolithische Kulturabfolge in Niederösterreich und den angrenzenden Gebieten. - Eisz. u. Geg. 7, 127-175, 1956.

BrunNACKER, K.: Der würmeiszeitliche Löß in Bayern. - Geol. Bavar. 19, 258-265, 1953. - - Die Geschichte der Böden im jüngeren Pleistozän in Bayern. - Geol.Bavar. 34, München 1957.

Büvel, J.: Die Klimaphasen der Würmeiszeit. - Naturwiss. 37, 438-449, 1950.

FINK, J.: Zur Korrelation der Terrassen und Lösse in Ósterreich. - Eisz. u. Geg. 7, 49-77, 1956.

Freising, H.: Gliederung und Alter des deutschen Lösses. - Actes IV. Congr. Int. Quaternaire 1953, 340, Rom 1956.

Graul, H.: Bemerkungen zu einer geologischen Übersichtskarte des Iller-Riß-Gebietes. - Z. deutsch. geol. Ges. 105 (1953), 517-524, 1955.

Graul, H. \& Schaefer, I.: Zur Gliederung der Würmeiszeit im Illergebiet. - Geol. Bavar. 18, München 1953.

Gross, H.: Das Göttweiger Interstadial, ein zweiter Leithorizont der letzten Vereisung. - Eisz. u. Geg. 7, 87-101, 1956. - - Die geologische Gliederung und Chronologie des Jungpleistozäns in Mitteleuropa und den angrenzenden Gebieten. - Quartär 9, 3-39, 1957. - Die bisherigen Ergebnisse von C14-Messungen und paläolithischen Untersuchungen für die Gliederung des Jungpleistozäns in Mitteleuropa und den Nachbargebieten. - Eisz. u. Geg. 9, 155-187, 1958.

Guenther, E. W.: Feinstratigraphische Untersuchung einer Zwischenschicht und der Deckschichten der Travertine von Ehringsdorf. - Alt-Thüringen 3, 1-15, 1958.

HaAse, C. \& Richter, H.: Fossile Böden im Löss an der Schwarzmeerküste bei Constanta. Peterm. geogr. Mitt. 101, 161-173, 1957.

HantKe, R.: Die Gletscherstände des Reuß- und Linthsystems zur ausgehenden Würmeiszeit. Eclog. geol. Helv. 51, 119-149, 1958.

KAHLKE, H.-D.: Die jungpleistozänen Säugetierfaunen aus dem Travertingebiet von TaubachWeimar-Ehringsdorf (Vorbericht). - Alt-Thüringen 3, 97-130, 1958.

Kleinschmidt, A.: Die zoologischen Funde der Grabung Salzgitter-Lebenstedt 1952. - Eisz. u. Geg. 3, 166-188, 1953.

KLímA, B.: Ưbersicht über die jüngsten paläolithischen Forschungen in Mähren. - Quartär 9, 85-130, 1957.

LindNER, H.: Besprechung von K. J. NARR: Das Rheinische Jungpaläolithikum 1955. - Quartär 9, 233-236, 1957.

Milankovitch, M.: Mathematische Klimalehre und Astronomische Theorie der Klimaschwankungen. - Handbuch der Klimatologie $I, A$. Berlin 1930. - Kanon der Erdbestrahlung und seine Anwendung auf das Eiszeitenproblem. - Belgrad 1941. 
MıLoJčı́́, V.: Zur Anwendbarkeit der C14-Datierung in der Vorgeschichtsforschung. - Germania 35, 102-110, 1957.

MülleR-BECK, H.: Das Obere Altpaläolithikum in Süddeutschland. - Bonn 1957 (1957 a). - Paläolithische Kulturen und Pleistozäne Stratigraphie in Süddeutschland. - Eisz. u. Geg. 8, 116-140, 1957 (1957 b). - - Zur allgemeinen und regionalen Stratigraphie des europäischen Jungpleistozäns. - Verh. V. Int. Kongr. Vor- u. Frühgesch. Hamburg 1958 (im Druck).

Müller-Beck, H., Oeschger, H., Schwarz, U.: Cl4-Datierung der neolithischen Siedlung Seeberg, Burgäschisee-Süd. Gruppenmessung und absolutes Alter. - Jb. Bern. Hist. Mus. 37/38 (1957/58), 1959 (im Druck).

Obermaier, H.: Der Mensch der Vorzeit. - Berlin 1913.

PENCK, A.: Säugetierfauna und Paläolithikum des jüngeren Pleistozäns in Mitteleuropa. - Abh. preuß. Akad. Wiss. 1938, 5, Berlin 1938.

Penck, A. \& Brǘckner, E.: Die Alpen im Eiszeitalter. - Leipzig 1901/09.

Preul, F.: Die geologische Bearbeitung des paläolithischen Fundplatzes bei Salzgitter-Lebenstedt. - Eisz. u. Geg. 3, 149-154, 1953.

Prošek, Fr. \& Ložé, V.: Stratigraphische Ubersicht des tschechoslowakischen Quartärs. - Eisz. u. Geg. 8, 37-90, 1957.

Richter, K.: Geröllmorphometrische und Einregelungsstudien in den pleistozänen Sedimenten der paläolithischen Fundstelle Salzgitter-Lebenstedt. - Eisz. u. Geg. 3, 155-160. 1953.

RiEK, G.: Die Eiszeitjägerstation am Vogelherd. - Tübingen 1934.

Rust, A.: Funde der Hamburger Kultur im Geschiebemergel bei Grömitz. - Germania 33, 256, 1955.

Soerget, W.: Lösse, Eiszeiten und paläolithische Kulturen. - Jena 1919. - - Die diluvialen Terrassen der Ilm und ihre Bedeutung für die Gliederung des Eiszeitalters. - Jena 1924. - Die Vereisungskurve. - Berlin 1937.

TAuber, H. \& DE VRIEs, Hl.: Radiocarbon measurements of Würm-interstadial samples from Jutland. - Eisz. u. Geg. 9, 69-71, 1958.

ToDE, A.: Einige archäologische Erkenntnisse aus der paläolithischen Freilandstation von Salzgitter-Lebenstedt. - Eisz. u. Geg. 3, 192-215, 1953.

Troll, C.: Der jungdiluviale Inn-Chiemseegletscher. - Forsch. z. deutsch. Landesk. 23/1, 1924. - Diskussion im Anschluß an F. Weidenbach 1956, s. d.

Vértes, L.: Die Höhle von Istállóskö. - Acta Archaeol. Acad. Scient. Hungaricae 5, 111-291, 1955.

DE VRIES, Hl.: Radiocarbon Dates for upper Eem and Würm-interstadial samples. - Eisz. u. Geg. 9, 10-17, 1958. - - Radiocarbon Dating of the fossil Soils at Ober-Fellabrunn. Proc. konik1. nederl. Akad. Wetensch., Ser.B., 62, 1, 84-91, 1959.

Weidenbach, F.: Gedanken zur Lößfrage. - Eisz. u. Geg. 2, 25-36, 1952. - - Zeitliche Einordnung der jungpleistozänen Ablagerungen Mitteleuropas. - Actes IV. Congr. Int. Quaternaire 1953, 891-897, Rom 1956.

Wernert, P.: Contribution à la Stratigraphie Paléontologique et Préhistorique de sédiments Quaternaires d'Alsace, Achenheim. - Mém. Serv. Carte géol. d'Alsace/Lorraine 14, Strasbourg 1957.

Woldstedt, P.: Saaleeiszeit, Warthestadium und Weichseleiszeit in Norddeutschland. - Eisz. u. Geg. 4/5, 34-48, 1954. - - Eine neue Kurve der Würmeiszeit. - Eisz. u. Geg. 9, 151-154, 1958 (1958a). - - Das Eiszeitalter, 2. Aufl., Bd. II, Stuttgart 1958 (1958 b). - - Besprechung von H. Müller-Beck 1957 a. - Eisz. u. Geg. 9, 192, 1958 (1958 c).

ZeissLer, H.: Vorbericht über die Molluskenfaunen aus den Schichten des Ehringsdorfer Quartärs. - Alt-Thüringen 3, 29-71, 1958.

Zotz, L. F.: Altsteinzeitkunde Mitteleuropas. - Stuttgart 1951.

Manuskr. eingeg. 6. 5. 1959.

Anschrift des Verf.: Dr. Hansjürgen Müller-Beck, Bern, Schönauweg 12. 